\title{
On the Relationship between the African Easterly Jet, Saharan Mineral Dust Aerosols, and West African Precipitation
}

\author{
Emily Bercos-Hickey, Terrence R. Nathan, and Shu-Hua Chen \\ Atmospheric Science Graduate Group, Department of Land, Air, and Water Resources, University of California, \\ Davis, Davis, California
}

(Manuscript received 2 October 2018, in final form 27 January 2020)

\begin{abstract}
The relationship between the African easterly jet (AEJ), Saharan mineral dust (SMD) aerosols, and West African precipitation (WAP) is examined using European Centre for Medium-Range Weather Forecasts interim reanalysis (ERA-Interim) data, the NASA Modern-Era Retrospective Analysis for Research and Applications, version 2 (MERRA-2), and the NASA Tropical Rainfall Measuring Mission (TRMM) Multisatellite Precipitation Analysis (TMPA) for July-September 1998-2017. The spatial orientation and structure of AEJs in different SMD-WAP environments are compared. In dustier years, the AEJ is farther east and stronger, rotates clockwise, and has larger zonal and vertical shears. In wetter years, the AEJ is farther north, has a shorter zonal extent, and has larger meridional shear. These changes to the AEJ are a response to the combined effects of the SMD and WAP on the thermal field, which is confirmed through sensitivity tests carried out with the Weather Research and Forecasting Model coupled to an interactive dust model.
\end{abstract}

\section{Introduction}

The summertime circulation over North Africa is a mosaic of currents, waves, aerosols, and precipitation. The two main currents are the upper tropospheric tropical easterly jet (Chen and van Loon 1987) and the midtropospheric African easterly jet (AEJ; Cook 1999). Associated with the AEJ are African easterly waves (AEWs), which propagate along two tracks that are located north and south of the AEJ (Reed et al. 1988). The AEJ-AEW system, low-level Harmattan winds, cold nearsurface outflow of convective systems, and nocturnal lowlevel jets are among the most prominent wind systems observed over North Africa (Jones et al. 2003; Knippertz and Todd 2012; Fiedler et al. 2013). These wind systems contribute to the episodic emissions of Saharan mineral dust (SMD) aerosols (Evan et al. 2016), which can form synoptic-scale plumes that occur north of the AEJ (Nathan et al. 2019). To the south of the AEJ is the intertropical convergence zone (Waliser and Somerville 1994), and enhanced West African precipitation (WAP) that is associated with the low-level southwesterly winds of the West African monsoon (WAM) (Sultan and Janicot 2003).

Corresponding author: Emily Bercos-Hickey, ebercosh@ ucdavis.edu
In this study, we cull from the above mosaic the AEJ, SMD, and WAP. The spatial distribution of the three fields is shown in Fig. 1. The AEJ not only has a strong influence on weather systems over North Africa (Wu et al. 2012), it also resides at the boundary between the SMD and WAP regions. Thus it is not surprising that studies have shown that there is a strong relationship between the AEJ and SMD (Reale et al. 2011) and between the AEJ and WAP (Grist and Nicholson 2001). But there has yet to be a comprehensive study of the response of the AEJ to the combined effects of SMD and WAP. This is the focus of our study, which is built on the following hypothesis: The SMD-WAP modified thermal field significantly changes the location, speed, and structure of the AEJ.

We begin with a brief review of the AEJ, SMD, and WAP. Consider first the AEJ, which is a midtropospheric jet with a summertime location of $\sim 15^{\circ} \mathrm{N}$ and $\sim 600 \mathrm{hPa}$ and a maximum speed of $\sim 12 \mathrm{~m} \mathrm{~s}^{-1}$ (Cook 1999). The AEJ is maintained by two diabatically forced circulations: dry convection to the north and moist convection to the south (Thorncroft and Blackburn 1999), each of which is affected by the orography and moisture gradients over North Africa (Wu et al. 2009). The dry convection that occurs north of the AEJ coincides with the latitudes of 


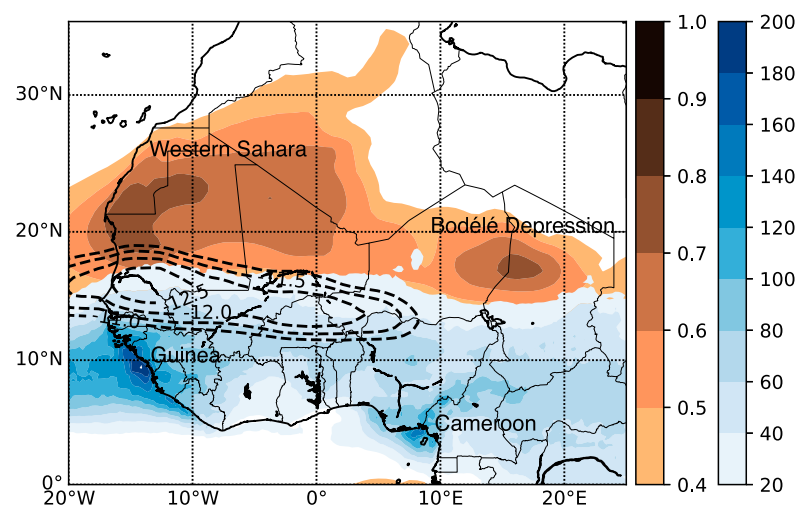

FIG. 1. ERA-Interim 600-hPa zonal wind in $\mathrm{m} \mathrm{s}^{-1}$ (black; dashed contours), MERRA-2 aerosol optical depth (AOD; browns), and TMPA accumulated rainfall in $\mathrm{cm}$ (blues), time averaged for JulySeptember for the years 1998-2017. Note that there is a slight overlap between the shaded contours of the AOD and accumulated rainfall.

large SMD emissions shown in Fig. $1 .^{1}$ The moist convection south of the AEJ is due to moisture advection from the Gulf of Guinea (Sultan and Janicot 2003).

The synoptic-scale plumes of SMD that form over North Africa affect the radiative balance of the atmosphere and surface, which, in turn, affects the AEJ (Reale et al. 2011; Bercos-Hickey et al. 2017) and WAP (Klüser and Holzer-Popp 2010; Solmon et al. 2012; Salah et al. 2018). The plumes are mostly transported toward the Atlantic Ocean (Kaufman et al. 2005), where they begin to diminish, although vestiges of the plumes have been measured as far away as the Americas (Engelstaedter et al. 2006).

Eighty percent of the rainfall in the Sahel occurs during July, August, and September (JAS) (Nicholson 2008, 2013), which is the prevailing period of the WAM (Parker et al. 2005; Nicholson 2013). Indeed, model results have shown a strong correlation between the WAM and the interannual variability of WAP (Diallo et al. 2013). The WAM develops during late spring and summer due to the northward advance of the sun (Sultan and Janicot 2003). The northward advance of maximum solar radiation is also the main driver of the Saharan heat low, which reaches its summer location about a week before the onset of the WAM (Lavaysse et al. 2009). The low-level cyclonic circulation of the Saharan heat low increases the southwesterly WAM flow, as well as the northeasterly Harmattan winds that contribute to SMD emissions (Lavaysse et al. 2009; Fiedler et al. 2013).

\footnotetext{
${ }^{1}$ The major SMD source regions over North Africa are the Bodélé Depression in Chad and parts of Mauritania, Mali, and Algeria (Engelstaedter and Washington 2007).
}

Progress has been made in understanding the interactions between the paired combinations AEJ-WAP, AEJ-SMD, and SMD-WAP. For example, Diallo et al. (2013) and Sylla et al. (2013) used regional climate models to show that during wet years the AEJ shifts north. Grist and Nicholson (2001) and Dezfuli and Nicholson (2011) used reanalysis data to show that during wet years the AEJ is weaker and shifts farther north and west. The weaker AEJ stems from the fact that the vertical wind shear of the AEJ must overcome greater lowlevel westerlies during wet years (Grist and Nicholson 2001). The northward shift of the AEJ is a result of the WAP-induced shift in the maximum temperature gradient (Nicholson and Grist 2003).

The AEJ-SMD relationship is such that the SMD strengthens the AEJ (Chen et al. 2010; Lavaysse et al. 2011; Grogan et al. 2017; Bercos-Hickey et al. 2017; N'Datchoh et al. 2018) and shifts it farther north and upward (Wilcox et al. 2010; Reale et al. 2011; Bercos-Hickey et al. 2017). The strengthening of the AEJ is partially due to thermal wind balance; SMD increases atmospheric heating north of and below the AEJ through absorption of solar radiation (Zhu et al. 2007; Chen et al. 2010), which strengthens the meridional temperature gradient. The thickness of the Saharan heat low also increases through dust-radiative interactions such that the midtropospheric anticyclonic circulation associated with the Saharan heat low intensifies, which further strengthens the AEJ (Lavaysse et al. 2011).

The SMD-WAP relationship has a strong two-way interaction (Klüser and Holzer-Popp 2010; Marticorena et al. 2010; Knippertz and Todd 2012). Consider first the effect of WAP on SMD. WAP can either increase or decrease SMD emissions depending on the physical processes involved. For example, WAP increases the amount of SMD aerosols through the cold outflow of mesoscale convective systems that produce large emissions called haboobs (Knippertz and Todd 2012). In contrast, WAP decreases the amount of SMD aerosols through wet scavenging and through suppressed SMD emission due to increased soil moisture (Marticorena et al. 2010).

Consider next the effect of SMD on WAP. SMD can also increase or decrease WAP. For example, SMD can increase WAP through midlevel warming that leads to large-scale onshore flow and deep convection over West Africa (Lau et al. 2009). Other studies show, however, that SMD can decrease WAP due to increased static stability from midlevel warming and surface cooling (Konaré et al. 2008; Solmon et al. 2012). Moreover, Klüser and Holzer-Popp (2010) show that SMD cloud condensation nuclei over West Africa reduce cloud droplet size and thus precipitation. 
This study addresses several unresolved questions of both practical and theoretical importance. Do SMD and WAP oppose or reinforce each other, and what does this mean for the thermal field and ultimately the maintenance of the AEJ? How does the interannual variability of SMD and WAP affect the location, strength, horizontal orientation, and spatial structure of the AEJ, and what are the potential consequences?

The article is organized as follows: section 2 describes the data and the methods of analysis. In section 3, the characteristics of the SMD and WAP fields are examined, followed by an analysis of the AEJ in different SMD and WAP environments in section 4. In section 5, the Weather Research and Forecasting Model, which is coupled to an interactive dust model, is used to conduct sensitivity experiments that further support our central hypothesis. The conclusions and discussion are presented in section 6 .

\section{Data and methods}

Three datasets are used to examine the relationship between the AEJ, SMD, and WAP: The European Centre for Medium-Range Weather Forecasts (ECMWF) interim reanalysis (ERA-Interim) dataset; the NASA ModernEra Retrospective Analysis for Research and Applications, version 2 (MERRA-2); and the NASA Tropical Rainfall Measuring Mission (TRMM) Multisatellite Precipitation Analysis (TMPA). The Weather Research and Forecasting (WRF) Model coupled to an interactive dust model is used to conduct sensitivity experiments that further support the reanalysis results.

\section{a. ERA-Interim}

ERA-Interim is a global atmospheric reanalysis dataset for 1979 to the present that has $0.7^{\circ} \times 0.7^{\circ}$ latitudelongitude resolution and 6-hourly gridded estimates of three-dimensional meteorological variables (Dee et al. 2011). The reanalysis dataset is produced using a sequential four-dimensional variational analysis system with 12-h cycles. In each cycle, observational data are combined with prior information from a model forecast. The combined data are then used to initialize a model that provides the prior information needed for the next analysis cycle.

The model used to produce the ERA-Interim reanalysis dataset is the ECMWF Integrated Forecast System (Dee et al. 2011). This model has three fully coupled components for the atmosphere, land, and ocean. Satellites provide the majority of the observational data used in conjunction with the model. Observational data from radiosondes, pilot balloons, aircraft, and wind profilers are also assimilated, although they provide a much smaller volume of data. The incorporation of observational data into the model short-term forecast produces a dataset of the global atmospheric evolution that is constrained by observations.

\section{b. MERRA-2}

MERRA-2 is a NASA atmospheric reanalysis dataset for 1980 to the present that has global coverage and $0.5^{\circ} \times 0.625^{\circ}$ latitude-longitude resolution (Gelaro et al. 2017; Randles et al. 2017; Buchard et al. 2017). MERRA-2 is produced using the Goddard Earth Observing System, version 5 (GEOS-5) data assimilation system (Molod et al. 2015) and the Gridpoint Statistical Interpolation analysis system (GSI; Kleist et al. 2009). Aerosols in MERRA-2 are simulated with the Goddard Chemistry, Aerosol, Radiation, and Transport (GOCART) model (Chin et al. 2002), which is coupled to the GEOS-5 data assimilation system. The GOCART model simulates dust, sea salt, black and organic carbon, and sulfate. The dust aerosols are broken into five, noninteracting particle sizes. Dust emissions are controlled by surface wind, soil moisture, and geographic region; dust removal is due to dry deposition, large-scale wet removal, and convective scavenging.

MERRA-2 aerosol analysis uses the Goddard Aerosol Assimilation System (GAAS), such that every $3 \mathrm{~h}$ the system assimilates bias-corrected aerosol optical depth (AOD) at $550 \mathrm{~nm}$ into the GEOS-5/GOCART model (Randles et al. 2017). Observations are obtained from several instruments, including the Advanced Very High Resolution Radiometer (AVHRR), the Moderate Resolution Imaging Spectroradiometer (MODIS) from the Terra and Aqua satellites, the Multiangle Imaging SpectroRadiometer (MISR) over the desert, and ground based measurements from the Aerosol Robotics Network (AERONET). Evaluation of MERRA-2 shows that both the MERRA-2 AOD and the vertical structure of aerosol properties are in good agreement with observational data (Buchard et al. 2017).

\section{c. TMPA}

TMPA provides precipitation estimates at a 3-hourly, $0.25^{\circ} \times 0.25^{\circ}$ latitude-longitude resolution and covers $50^{\circ} \mathrm{N}$ to $50^{\circ} \mathrm{S}$ for 1998 to the present (Huffman et al. 2007). The dataset combines information from both satellite systems and surface precipitation gauge analysis. Satellite system data are broken into two parts: precipitation-related microwave data and the window channel $(\sim 10.7 \mu \mathrm{m})$ infrared (IR) data. Sources for precipitation gauge analysis include the Global Precipitation Climatology Project (GPCP) monthly rain gauge analysis and the Climate Assessment and Monitoring System (CAMS) monthly rain gauge analysis. 
Precipitation-related microwave data are collected by a variety of sensors on low Earth orbit satellites, such as TRMM Microwave Imager (TMI) on TRMM and Advanced Microwave Scanning Radiometer-Earth Observing System (AMSR-E) on Aqua. Alone, the satellites provide sparse data coverage; combining the satellite data improves coverage, although there are still significant gaps. Passive microwave fields of view from the satellite sensors are converted to precipitation estimates with sensor-specific algorithms, such as the Goddard Profiling Algorithm (Kummerow and Giglio 1994).

The IR data are collected by the international constellation of geosynchronous Earth orbit (GEO) satellites. In contrast to the microwave satellite data, which are sparse, the GEO-IR data have excellent time-space coverage. The brightness temperatures gathered from the IR data primarily correspond to cloud-top temperature, and implicitly cloud height. Although the GEO-IR data are not a good estimate for precipitation on fine time and space scales, they are well correlated with precipitation on time scales of about one day and spatial scales of about $0.25^{\circ} \times 0.25^{\circ}$ latitude-longitude resolution (Arkin and Meisner 1987).

As detailed in Huffman et al. (2007), the satellite and rain gauge data are processed in four stages to produce the TMPA estimates. First, the microwave precipitation estimates are calibrated and combined. Data from each satellite sensor are averaged to the $0.25^{\circ}$ spatial grid and calibrated using TRMM data. The spatial grid is then populated by data available for each grid box, and an average is taken when a grid box has data available from multiple sensors. Second, microwave precipitation rates are temporally and spatially matched with IR brightness temperatures to create calibration coefficients that convert brightness temperatures to precipitation rates. The calibration coefficients are then applied to the entire IR dataset. Third, the microwave and IR precipitation rates are combined such that the microwave estimates are used when available, and any remaining grid boxes are filled with IR estimates. Lastly, rain gauge data are used to scale the merged microwave-IR (M-IR) estimates. The rain gauge data are combined with the M-IR estimates to create a satellite-gauge (SG) dataset. The field of SG/M-IR ratios is computed on the $0.25^{\circ} \times 0.25^{\circ}$ grid and is used to scale the precipitation estimates.

\section{d. WRF-dust model}

The WRF-dust model (Chen et al. 2010, 2015) is a modified version of WRF 3.7.1 (Skamarock et al. 2008) and is radiatively coupled to an interactive dust model. The evolution of SMD is governed by a dust continuity equation, wherein the rate of change of the mass coupled dust mass mixing ratio is due to the flux divergence of SMD, mixing of SMD by boundary layer turbulence and subgrid-scale convection, sedimentation, scavenging, dry and wet deposition, and surface emission. Surface emission occurs when the vegetation type is barren, the soil volumetric moisture is less than 0.2 , and the $10-\mathrm{m}$ wind speed exceeds a threshold of $6 \mathrm{~m} \mathrm{~s}^{-1}$ (Tegen and Fung 1994; Chen et al. 2010). The SMD radiative effects are included using the shortwave radiation scheme of the Rapid Radiative Transfer Model for Global Climate Models (Iacono et al. 2008).

The WRF-dust model uses five SMD particle sizes with median radii of $0.25,0.5,1.0,2.0$, and $4.0 \mu \mathrm{m}$ to represent the spectrum of mineral dust sizes over North Africa. Each particle size is governed by its own continuity equation. The aerosol properties of the different SMD sizes are calculated using the Optical Properties of Aerosols and Clouds (OPAC) software package (Hess et al. 1998). The SMD optical properties include the asymmetry parameter, single scatter albedo, and extinction coefficient, all as a function of wavelength and SMD particle size. The coefficients of the optical properties are stored in look-up tables to be used in the radiation schemes of the WRF-dust model.

\section{e. Methods}

The relationship between the AEJ, SMD, and WAP is examined for JAS for the years 1998-2017. The 20 years span the availability of the TMPA dataset. The analysis focuses on North Africa and the eastern Atlantic Ocean, which together encompass the AEJ and areas of SMD emissions and WAP. The analysis uses the following fields: the 6-hourly zonal wind and temperature from the ERA-Interim data, the 3-hourly AOD from MERRA-2, and the 3-hourly precipitation rate from TMPA. Accumulated rainfall is calculated from the precipitation rates by multiplying each rate by $3 \mathrm{~h}$ and summing the precipitation values for each JAS period.

JAS time averages are calculated for each year and are used to calculate averages for groups of years. Area averaging is also used to determine years of more or less SMD and WAP, and to analyze the location, magnitude, and structure of the AEJ. Zonal wind, AOD, and accumulated rainfall averages and extrema are calculated for each year. Correlations are calculated to determine relationships between the zonal wind, AOD, and accumulated rainfall.

\section{SMD and WAP}

We define the total SMD region as $10^{\circ}-30^{\circ} \mathrm{N}$ and $20^{\circ} \mathrm{W}-20^{\circ} \mathrm{E}$. Within this region there are two maxima in AOD, one over the western Sahara and the other over the Bodélé Depression (Fig. 1). These two regions are 
major sources of SMD over North Africa (Engelstaedter and Washington 2007). The total SMD region will be used to calculate the spatial-temporal average of AOD for each year.

We define the total WAP region as $0^{\circ}-25^{\circ} \mathrm{N}, 20^{\circ} \mathrm{W}-$ $20^{\circ} \mathrm{E}$, based on Nicholson et al. (2000). Within this region, the majority of the rainfall occurs within $5^{\circ}-15^{\circ} \mathrm{N}$, with maxima off of the coast of Guinea and Cameroon (Fig. 1). Although the total WAP region contains local areas that may be significantly drier or wetter than the regional average, our focus is on the broader synoptic scale. For this reason, the total WAP region will be used to calculate the spatial-temporal average of accumulated rainfall for each year.

The interannual variability of SMD and WAP has been related to El Niño-Southern Oscillation (ENSO) (DeFlorio et al. 2016; Pomposi et al. 2016). Some studies have chosen to examine the meteorology over North Africa in ENSO-neutral years (Wu et al. 2012). For completeness, we analyze the relationship between SMD, WAP, and ENSO using the National Oceanic and Atmospheric Administration Oceanic Niño Index (ONI). We find no correlation between the average AOD and the ONI. We find a moderate negative correlation between the average accumulated rainfall and the ONI $(r=-0.50, p<0.05)$. This correlation is consistent with previous studies that have found that WAP is less during the El Niño phase and greater during the La Niña phase (Hastenrath 1990; Moron and Ward 1998; Pomposi et al. 2016). Despite this correlation, we do not remove ENSO years from this study as they are an integral part of the interannual variability of the region under consideration.

We next compare the interannual variability of SMD and WAP. Figure $2 \mathrm{a}$ shows the standardized departures from the 20-yr mean of the accumulated rainfall for the total WAP region (blue) and of the AOD for the total SMD region (brown). El Niño years are denoted with diagonal hatching and La Niña years are denoted with horizontal hatching.

From Fig. 2a, we define four SMD-WAP groupings based on above or below average AOD and accumulated rainfall: 1) years that are wetter and less dusty (WLD), 2) years that are wetter and more dusty (WMD), 3) years that are drier and less dusty (DLD), and 4) years that are drier and more dusty (DMD). The frequency of each of the four SMD-WAP groupings is about the same: four WLD years $(1999,2010,2012,2016)$, six WMD years (1998, 2003, 2006, 2007, 2008, 2017), five DLD years $(2004,2011,2013,2014,2015)$, and five DMD years $(2000$, 2001, 2002, 2005, 2009). To better visualize the four groupings, we show in Fig. $2 \mathrm{~b}$ the standardized departures of accumulated rainfall and AOD organized by
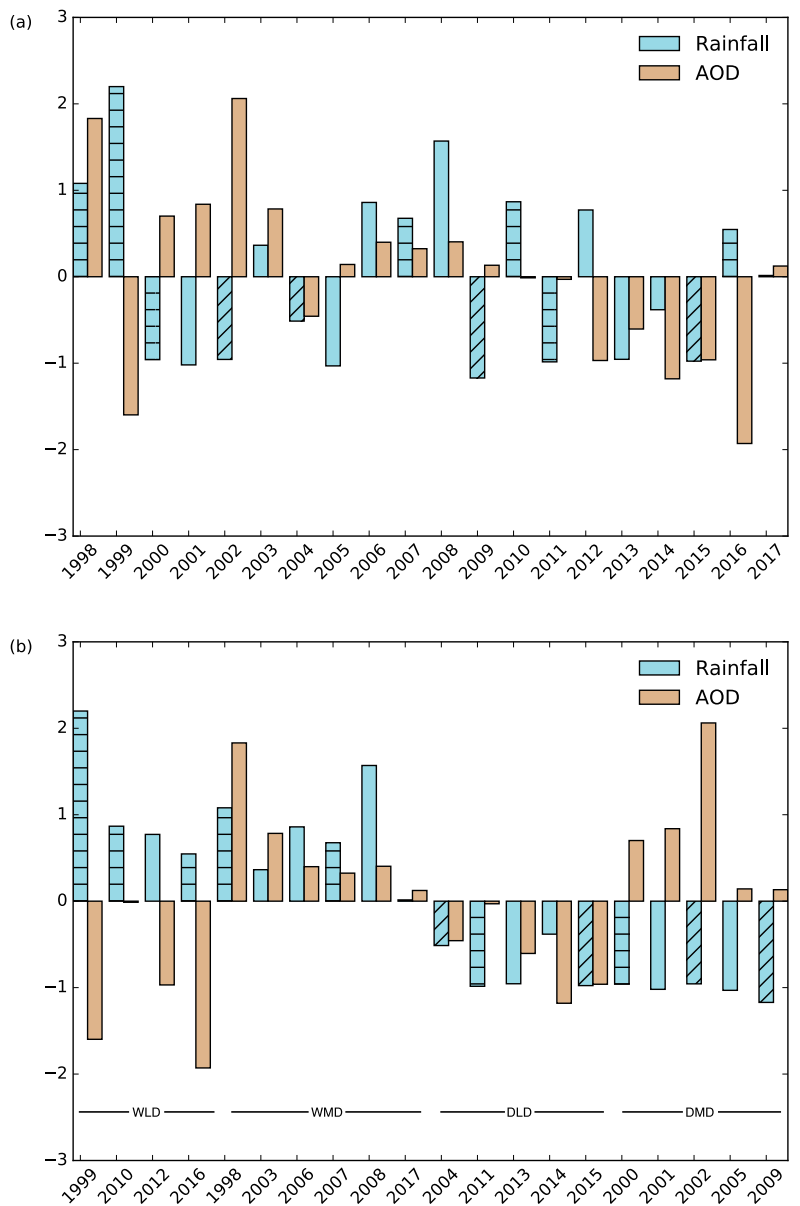

FIG. 2. July-September standardized departures for total average TMPA accumulated rainfall (blue) and total average MERRA-2 AOD (brown), ordered (a) chronologically and (b) by SMD-WAP grouping. Diagonal and horizontal hatches denote El Niño and $\mathrm{La}$ Niña years, respectively.

SMD-WAP grouping, as opposed to the chronological distribution shown in Fig. 2a.

Figure 3 shows the temperature differences between the four SMD-WAP groupings. To examine the effect of WAP, $600-\mathrm{hPa}$ temperature difference plots are shown for (a) WMD minus DMD and (b) WLD minus DLD. To examine the effect of SMD, 750-hPa temperature difference plots are shown for (c) WMD minus WLD and (d) DMD minus DLD. The 600- and 750-hPa levels are chosen because they show most clearly the effects of cloud latent heating and dust heating, respectively. In Figs. 3a and 3b, there are positive temperature anomalies over North Africa between $\sim 0^{\circ}$ and $20^{\circ} \mathrm{N}$. This is indicative of increased latent heating from WAP in the wetter groupings (WLD and WMD). Figures $3 \mathrm{c}$ and $3 \mathrm{~d}$ show positive temperature anomalies over the Sahara between $\sim 10^{\circ}$ and $35^{\circ} \mathrm{N}$. This is indicative of increased heating from SMD over North Africa 

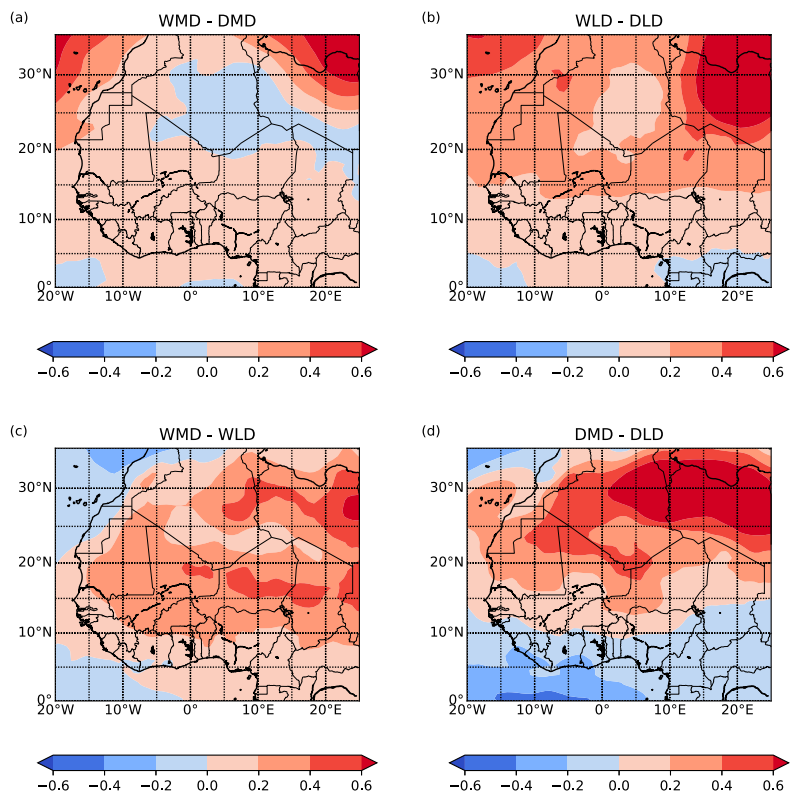

FIG. 3. ECMWF temperature differences in kelvin at $600 \mathrm{hPa}$ for (a) WMD minus DMD and (b) WLD minus DLD, and at $750 \mathrm{hPa}$ for (c) WMD minus WLD and (d) DMD minus DLD.

in the dustier groupings (WMD and DMD). As shown in the next section, these SMD- and WAP-modified changes to the thermal field manifest in changes to the strength and structure of the AEJ.

\section{African easterly jet}

\section{a. Location, magnitude, and structure}

The relationship of the AEJ to SMD and WAP is examined using ERA-Interim zonal wind data for the period spanning 1998-2017. We group the 20 years of data based on the four SMD-WAP groupings defined in section 3. Figure 4 shows the locations of the JAS averaged maximum AEJ wind speed of zonal wind composites for WLD, WMD, DLD, and DMD; larger circles indicate a stronger wind speed. Significance tests are used to compare the magnitude and location of the maximum easterly wind speed of the AEJ for the 92 days of data in each of the four SMD-WAP groupings. These tests show that the differences between the four groupings are significant; the largest $p$ value from the intercomparisons of the four groupings is less than 0.10 and the average $p$ value is less than 0.05 .

Figure 4 shows that the AEJ maxima are $\sim 1^{\circ}-2^{\circ}$ farther north in wetter years (WLD, WMD) than in drier years (DLD, DMD), in agreement with Grist and Nicholson (2001), Diallo et al. (2013), and Sylla et al. (2013). Figure 4 also shows that the zonal location and magnitude of the AEJ are related to SMD. For example, the AEJ maxima

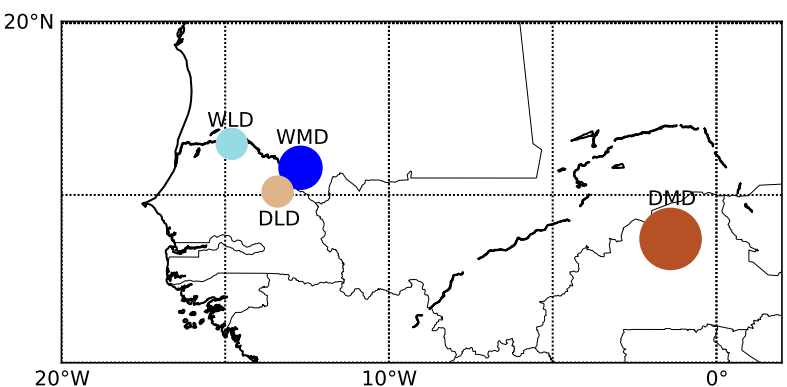

FIG. 4. Location of the AEJ maximum for years that are wetter with less than average dust (WLD), wetter with more than average dust (WMD), drier with less than average dust (DLD), and drier with more than average dust (DMD). Larger circles indicate a larger AEJ maximum wind speed.

of DMD and WMD are $\sim 2^{\circ}-12^{\circ}$ farther east and $\sim 5 \%$ larger in magnitude than WLD and DLD. Within each year, the strength of the AEJ is also larger in the dustier groupings. Dustier years have a larger number of days where the AEJ maximum is greater than the 20-yr average daily maximum wind speed.

Figure 4 highlights two other important findings. First, the AEJ is farther northwest during wetter, less dusty years (WLD) and farther southeast during drier, more dusty years (DMD). Second, although surface westerlies likely play a role in weakening the AEJ during wetter years, the fact that the AEJ is stronger in wetter, more dusty years (WMD) compared to drier, less dusty years (DLD) underscores the importance of SMD to changes in the AEJ.

Figure 5 shows JAS averaged vertical cross sections of zonal wind composites for (a) WLD, (b) WMD, (c) DLD, and (d) DMD. The cross sections are shown at the longitude of the AEJ maximum easterly wind speed for each SMD-WAP grouping seen in Fig. 4. The midtropospheric AEJ, the upper-tropospheric tropical easterly jet, and the low-level Harmattan and monsoon winds are all visible in Fig. 5. In all four SMD-WAP groupings, changes in the altitude of the AEJ along its longitudinal axis are small, ranging from $\sim 10$ to $30 \mathrm{hPa}$. Figure 5 shows that in wetter years the AEJ shifts north by $\sim 1^{\circ}-2^{\circ}$ and upward by $\sim 25 \mathrm{hPa}$. Additionally, in dustier years the maximum easterly wind speed is $\sim 5 \%$ larger than in less dusty years. Although previous studies have shown that the SMD-modified AEJ shifts north and upward (Reale et al. 2011; Bercos-Hickey et al. 2017), these studies use model data and do not consider WAP effects.

The AEJ core is used to examine the horizontal structure of the AEJ, where we define the core as the region between the maximum easterly wind speed and $95 \%$ of its maximum. To determine the horizontal orientation of the AEJ, we use a linear regression of the points in the AEJ core to form an AEJ axis. The angle 
(a)

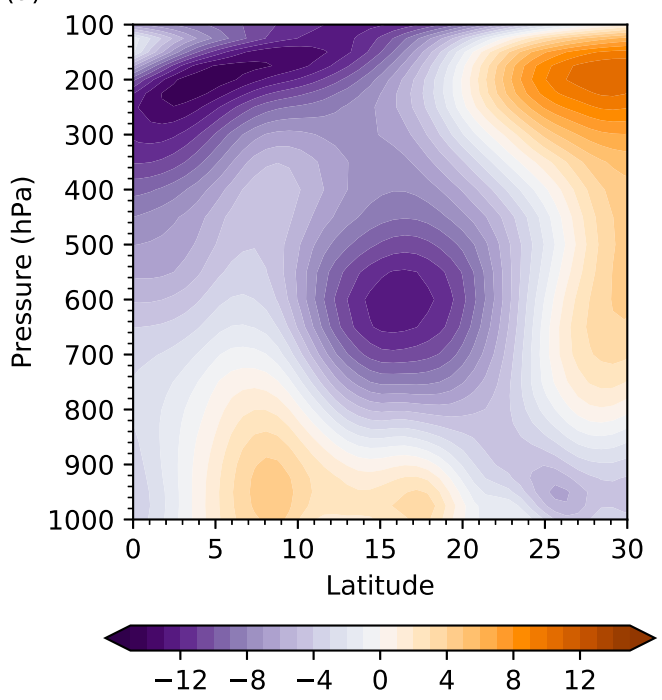

(c)

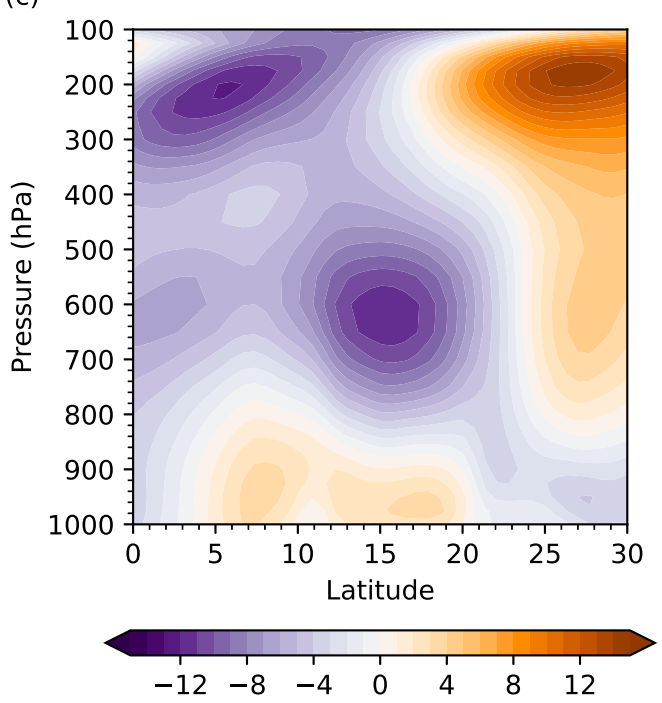

(b)

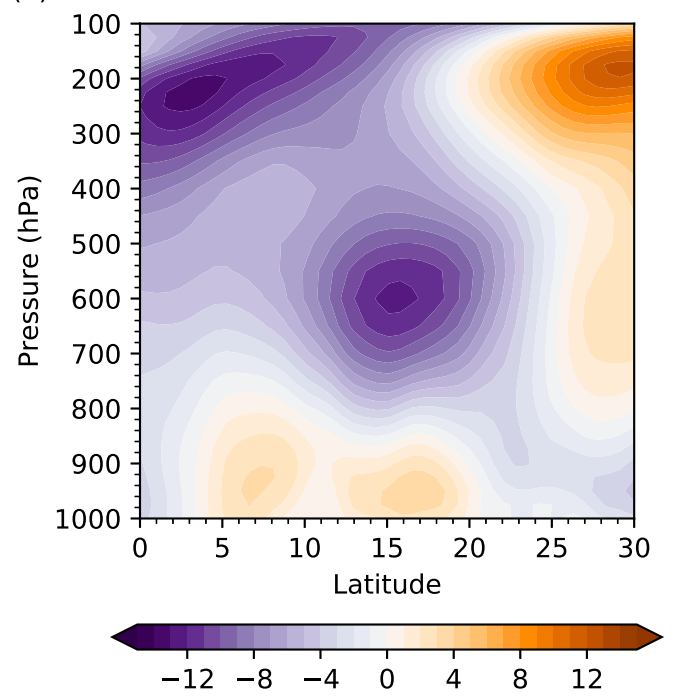

(d)

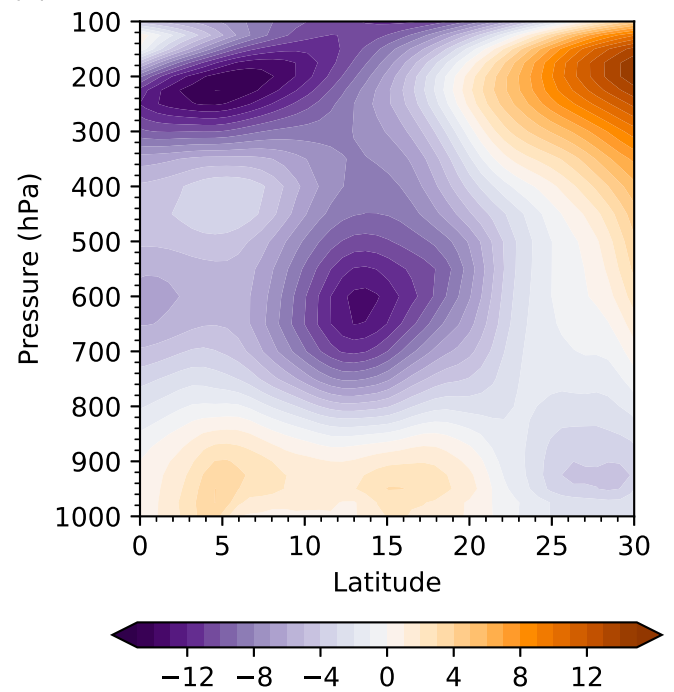

FIG. 5. Vertical cross sections of July-September time-averaged zonal wind composites in $\mathrm{m} \mathrm{s}^{-1}$ at the longitude of the maximum easterly wind speed for (a) WLD, (b) WMD, (c) DLD, and (d) DMD.

between the AEJ axis and lines of constant latitude measures the rotation of the AEJ.

Figure 6 shows the JAS averaged composite zonal wind at the height of the jet maxima for the four SMD-WAP groupings; the dashed black contours denote $95 \%$ of the maximum easterly wind speed. Figure 6 shows that the length of the AEJ core in WLD is $\sim 30 \%$ shorter than in DLD. Similarly, the length of the AEJ core in WMD is $\sim 50 \%$ shorter than in DMD. Thus the length of the AEJ core is shorter during wetter years and longer during drier years, regardless of SMD. In contrast, the width of the AEJ core is on average only $\sim 5 \%$ narrower in wetter years.
Figure 6 also shows the variability of the AEJ orientation (rotation) in the horizontal plane for the four SMD-WAP groupings. The AEJ rotates clockwise in all of the SMD-WAP groupings, with the largest rotations occurring in dustier years. For example, the largest rotation occurs in DMD (Fig. 6d), where the jet axis is rotated $\sim 8^{\circ}$. The rotations in WMD (Fig. 6b) and DLD (Fig. $6 \mathrm{c}$ ) are both $\sim 6^{\circ}$. The rotation in WLD (Fig. 6a) is only $\sim 4^{\circ}$. The rotation of the WMD AEJ is $\sim 50 \%$ larger than WLD, while the rotation of the DMD AEJ is $\sim 30 \%$ larger than DLD. Thus it is not so much the lack of WAP but rather the increase in SMD that is related to the increased rotation of the AEJ axis. 

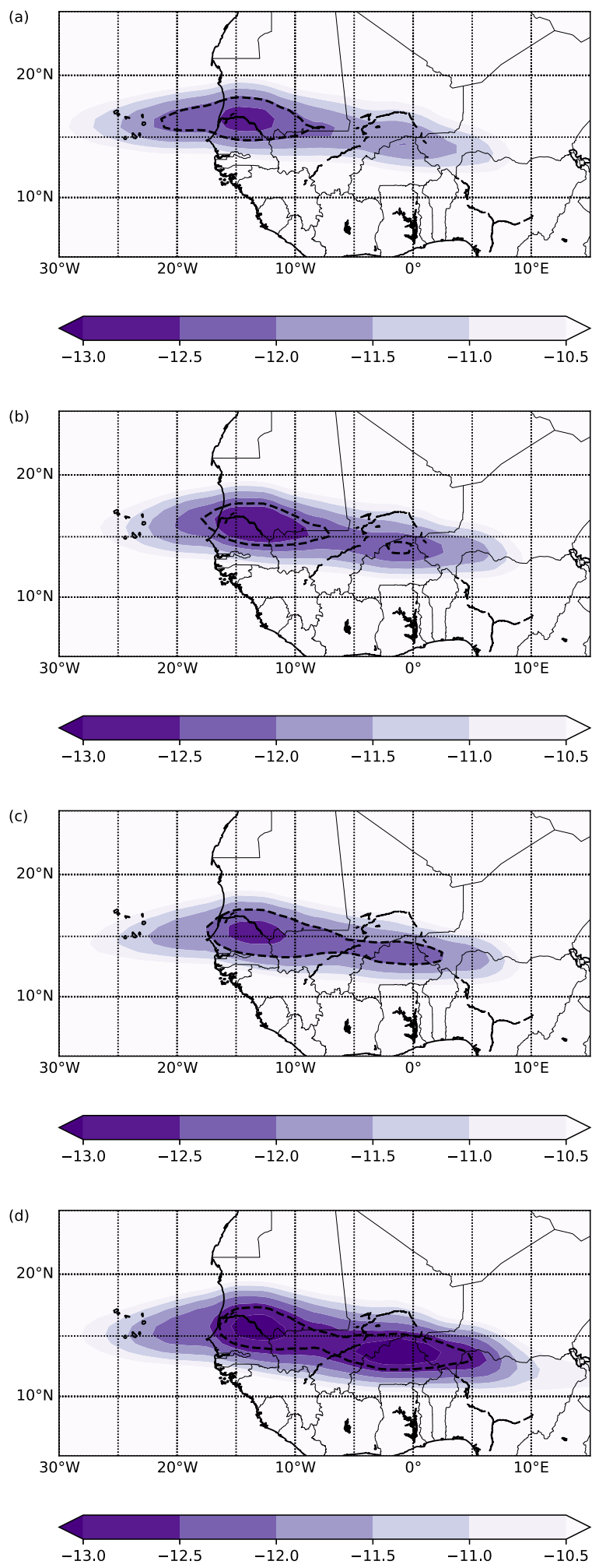

FIG. 6. July-September time-averaged zonal wind composites in $\mathrm{m} \mathrm{s}^{-1}$ at the altitude of the AEJ core for (a) WLD, (b) WMD, (c) DLD, and (d) DMD. Dashed contours indicate $95 \%$ of maximum easterly wind speed.

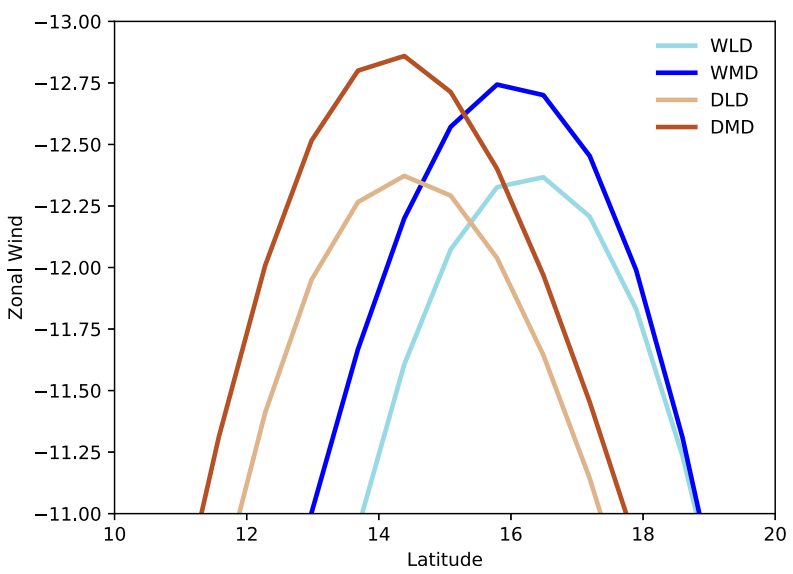

FIG. 7. Zonal wind profiles in $\mathrm{m} \mathrm{s}^{-1}$ at the height of the AEJ maxima (see Table 1) for WLD (light blue), WMD (dark blue), DLD (light brown), and DMD (dark brown), time averaged over July-September and zonally averaged at the AEJ core.

\section{b. Wind shear and asymmetry}

The horizontal and vertical shears of the AEJ are associated with barotropic and baroclinic energy conversions and are therefore central to understanding the energetics of the AEJ-AEW system (Hsieh and Cook 2007; Bercos-Hickey et al. 2017).

\section{1) Meridional SHEAR AND STRUCTURE}

The meridional shear in WLD and WMD is on average $\sim 5 \%$ larger than in DLD and DMD. Thus regardless of SMD, the meridional shear of the AEJ is stronger in wetter years. Figure 7 shows the meridional structure of the AEJ at the height of the jet maxima and zonally averaged at the AEJ core of each SMD-WAP grouping. Dustier years (dark blue and dark brown) have similar meridional structures, as do less dusty years (light blue and light brown). Consistent with the results in section $4 \mathrm{a}$, the zonally averaged strength of the AEJ is larger in dustier years; the AEJ maximum is up to $\sim 5 \%$ larger in WMD (dark blue) and DMD (dark brown) when compared with WLD (light blue) and DLD (light brown). Figure 7 also shows that the AEJ core is meridionally asymmetric around the maximum easterly wind speed. The asymmetry is enhanced in wetter or dustier years. For example, the asymmetry is greater in WLD and DMD, with the southern side of the AEJ core on average $\sim 40 \%$ wider than the northern side. In contrast, WMD and DLD show less asymmetry, with the northern side of the AEJ core on average $\sim 10 \%$ wider. Previous studies have shown that the zonal asymmetry of the AEJ affects the zonal expansion and contraction of AEWs (Hall et al. 2006; Bercos-Hickey et al. 2017). 


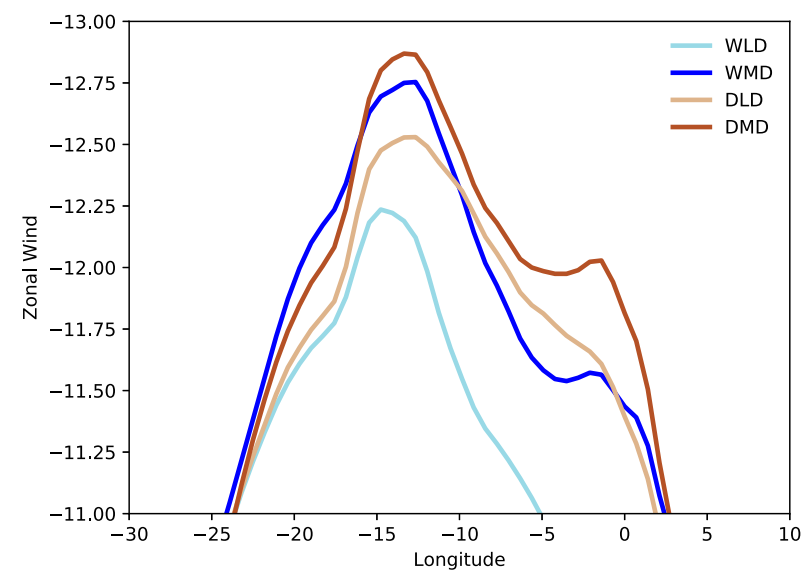

FIG. 8. Zonal wind profile in $\mathrm{ms}^{-1}$ at the height of the AEJ maxima (see Table 1) for WLD (light blue), WMD (dark blue), DLD (light brown), and DMD (dark brown), time averaged over July-September and meridionally averaged at the AEJ core.

\section{2) ZONAL SHEAR AND STRUCTURE}

In contrast to the meridional shear, which is associated with WAP, the zonal shear is associated with SMD. For example, the zonal shear for WMD and DMD is on average $\sim 20 \%$ larger than the zonal shear for WLD and DLD. Figure 8 shows the zonal structure of the AEJ at the height of the jet maxima and meridionally averaged at the AEJ core of each SMD-WAP grouping. Like Fig. 7, Fig. 8 shows similar zonal structures between years with more SMD (dark blue and dark brown) and between years with less SMD (light blue and light brown). The AEJ maximum is also up to $\sim 5 \%$ larger in WMD (dark blue) and DMD (dark brown) when compared with WLD (light blue) and DLD (light brown). This further confirms the relationship between SMD and the strength of the AEJ.

Figure 8 also shows that the AEJ core has greater zonal asymmetry around the maximum easterly wind speed in dustier years. For example, in WMD and DMD the western side of the AEJ core is on average $~ 30 \%$ wider than the eastern side, whereas in WLD and DLD the eastern side of the AEJ core is on average $\sim 10 \%$ wider than the western side. Thus there is greater downstream expansion of the AEJ core in dustier years. Using model data, Bercos-Hickey et al. (2017) also found that the zonal structure of the AEJ experiences greater downstream expansion with SMD. This downstream expansion of the AEJ manifests in the zonal expansion of the AEWs (Bercos-Hickey et al. 2017).

\section{3) Vertical SHEAR AND STRUCTURE}

The vertical shear is on average $\sim 10 \%$ larger in dustier years when compared with less dusty years. The vertical structure of the AEJ core also exhibits asymmetry, which is enhanced in either wetter or dustier years. For example, in WLD and DMD, the portion of the AEJ core above the altitude of the peak wind speed is on average $\sim 50 \%$ wider than the portion below. In contrast, in WMD and DLD, the AEJ core above the altitude of the peak wind speed is on average $\sim 5 \%$ wider than below.

\section{Sensitivity experiments}

The results presented above, which were obtained from an analysis of several datasets, support our original hypothesis: The SMD-WAP modified thermal field significantly changes the location and structure of the AEJ. Our analysis, however, does not address causality. It is conceivable that the adjustment to the thermal field may be due to forcings operating over North Africa that we have not considered. Thus, to further test our hypothesis, and to place the connection between the SMD-WAP modified thermal field and the AEJ on firmer physical and dynamical footing, we next conduct sensitivity tests using the WRF-dust model.

The sensitivity tests hinge on reducing the diabatic heating effects due to the SMD and WAP in the model and examining the response of the thermal field. This model approach should not be viewed as a way to replicate multiple years of reanalysis data; rather, it is a simple way to isolate the relationship between SMD and WAP and the thermal field. To reduce the SMD heating effects, dust emissions in the model are reduced by $50 \%$. To reduce the WAP heating effects, the surface latent heat flux is reduced by $10 \%$ in the model and the water vapor mixing ratio is reduced by $10 \%$ in the model's initial and boundary conditions.

Four experiments were run: 1) moisture and dust (MOIST_DUST), 2) moisture and reduced dust (MOIST R-DUST), 3) reduced moisture and dust (R-MOIST DUST), and 4) reduced moisture and reduced dust (R-MOIST_R-DUST). The four experiments correspond to the four SMD-WAP groupings: wetter and dustier, wetter and less dusty, drier and dustier, and drier and less dusty.

To carry out comprehensive sensitivity tests for the 20 summer seasons is beyond the scope of this study. Thus we chose a single year, JAS 1998, for the four WRF-dust experiments. This year is chosen because the AOD and the accumulated rainfall are above average (see Fig. 2), which results in larger differences between the four WRF-dust experiments, and therefore will more clearly expose the effects of SMD and WAP on the thermal field. We use the same model specifications as in Bercos-Hickey et al. (2017): 6-hourly output; two domains with $36-\mathrm{km}$ outer and $12-\mathrm{km}$ inner domain 

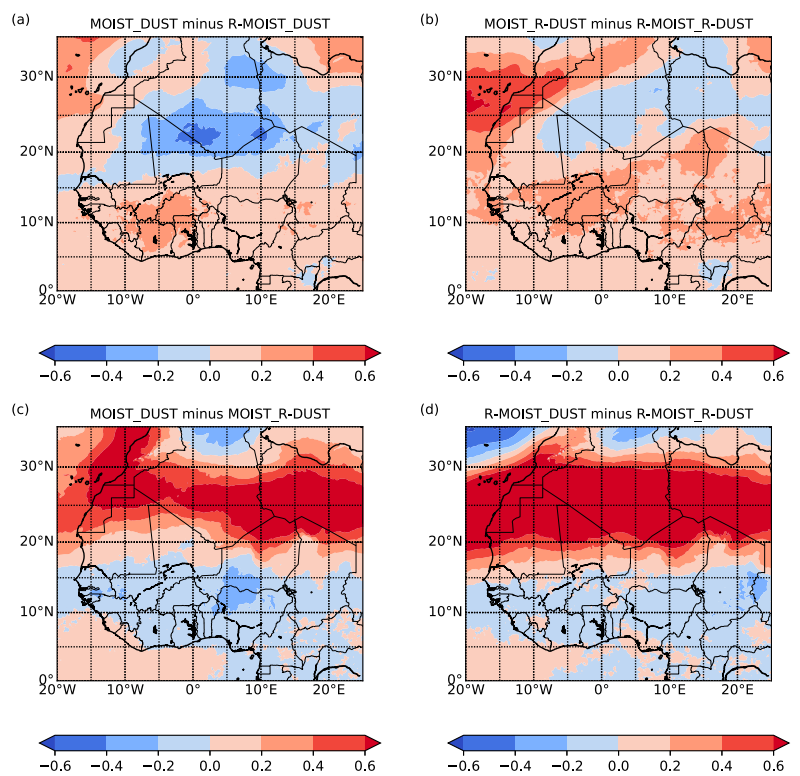

FIG. 9. WRF temperature differences in kelvin at $600 \mathrm{hPa}$ for (a) MOIST_DUST minus R-MOIST_DUST and (b) MOIST_ R-DUST minus R-MOIST_R-DUST, and at $750 \mathrm{hPa}$ for (c) MOIST_ DUST minus MOIST_R-DUST and (d) R-MOIST_DUST minus R-MOIST_R-DUST.

grid spacing; two-way interaction; the Rapid Radiative Transfer Model for Global Climate Models (Iacono et al. 2008) radiation scheme; the two-moment microphysics scheme (Cheng et al. 2010); the Medium Range Forecast (MRF) boundary layer parameterization (Hong and Pan 1996); and subgrid-scale cumulus parameterization (Kain 2004).

Figure 9 shows temperature differences for each of the four experiments. As in Fig. 3, the 600- and 750-hPa levels are used to examine the effects of WAP and SMD, respectively. The 600-hPa temperature difference plots are shown for MOIST_DUST minus R-MOIST_DUST (Fig. 9a) and MOIST_R-DUST minus R-MOIST_R-DUST (Fig. 9b). The 750-hPa temperature difference plots are shown for MOIST_DUST minus MOIST_R-DUST (Fig. 9c) and R-MOIST_DUST minus R-MOIST_R-DUST (Fig. 9d). The key features of the differences in the thermal fields obtained from the reanalysis data (Fig. 3) and the WRF-dust experiments (Fig. 9) are similar. For example, Figs. $3 \mathrm{a}$ and $3 \mathrm{~b}$ and Figs. $9 \mathrm{a}$ and $9 \mathrm{~b}$ show WAP-related warming between $\sim 0^{\circ}$ and $20^{\circ} \mathrm{N}$, while Figs. $3 \mathrm{c}$ and $3 \mathrm{~d}$ and Figs. $9 \mathrm{c}$ and $9 \mathrm{~d}$ show SMD-related warming between $\sim 15^{\circ}$ and $30^{\circ} \mathrm{N}$. The most similarity occurs between Figs. 3a and 9a and Figs. 3d and 9d, indicating that MOIST_DUST minus R-MOIST_DUST and R-MOIST_ DUST minus R-MOIST_R-DUST accurately capture the relationship between the SMD, WAP, and the thermal field.
TABLE 1. African easterly jet speed, location, and axis orientation relative to a parallel of latitude. Values are July-September averages from the four groupings: years that are wetter with less than average dust (WLD), wetter with more than average dust (WMD), drier with less than average dust (DLD), and drier with more than average dust (DMD).

\begin{tabular}{lrrrr}
\hline \multicolumn{1}{c}{ AEJ characteristics } & WLD & WMD & DLD & DMD \\
\hline Maximum wind speed $\left(\mathrm{m} \mathrm{s}^{-1}\right)$ & -12.7 & -13.0 & -12.7 & -13.4 \\
$\begin{array}{l}\text { Latitude of maximum } \\
\quad \text { ind speed }\end{array}$ & $16.5^{\circ}$ & $15.8^{\circ}$ & $15.1^{\circ}$ & $13.7^{\circ}$ \\
$\begin{array}{l}\text { Longitude of maximum } \\
\quad \text { wind speed }\end{array}$ & $-14.8^{\circ}$ & $-12.7^{\circ}$ & $-13.4^{\circ}$ & $-1.4^{\circ}$ \\
$\begin{array}{l}\text { Pressure level (hPa) of } \\
\text { maximum wind speed }\end{array}$ & 600 & 600 & 625 & 625 \\
\begin{tabular}{l} 
Clockwise rotation \\
\hline
\end{tabular} & $3.8^{\circ}$ & $5.9^{\circ}$ & $5.9^{\circ}$ & $8.3^{\circ}$ \\
\hline
\end{tabular}

There are, however, sharp differences between Figs. 3 and 9. For example, relative to Fig. 9, Fig. 3 shows less SMD-induced warming north of the AEJ and less WAP-induced warming south of the AEJ. This is a consequence of how the SMD and WAP heating fields are handled in the experiments. The MOIST_DUST and MOIST_R-DUST average accumulated rainfall is $\sim 20 \%$ larger than in R-MOIST_DUST and R-MOIST_R-DUST. In contrast, the average accumulated rainfall in the wetter groupings (WLD, WMD), which is associated with WAP effects, is only $\sim 15 \%$ larger than in the drier groupings (DLD, DMD). Thus we see less WAP-induced warming in Fig. 3 when compared with Fig. 9. The MOIST_DUST and R-MOIST_DUST average AOD is $\sim 80 \%$ larger than in MOIST_R-DUST and R-MOIST R-DUST experiments. In contrast, the average AOD in the dustier groupings (WMD, DMD), which is associated with SMD effects, is only $\sim 12 \%$ larger than the less dusty groupings (WLD, DLD). Thus we see larger SMDinduced heating differences and larger variability in the location of the temperature anomalies shown in Figs. 9c and $9 \mathrm{~d}$ when compared with Figs. $3 \mathrm{c}$ and $3 \mathrm{~d}$. The larger differences between Figs. $3 b$ and $9 b$ and Figs. $3 c$ and $9 c$ are also indicative of other mechanisms, such as the large-scale circulation, that affect the thermal field but were not considered in the WRF experiments in this study. Despite the differences between Figs. 3 and 9, the overall conclusions remain the same: the SMD-WAP modified heating field is a cause for the changes in the AEJ.

\section{Conclusions and discussion}

The African easterly jet (AEJ), Saharan mineral dust (SMD) aerosols, and West African precipitation (WAP) comprise a complex system that exerts its influence on weather within its North African home of origin and beyond. Our study is built on the hypothesis 

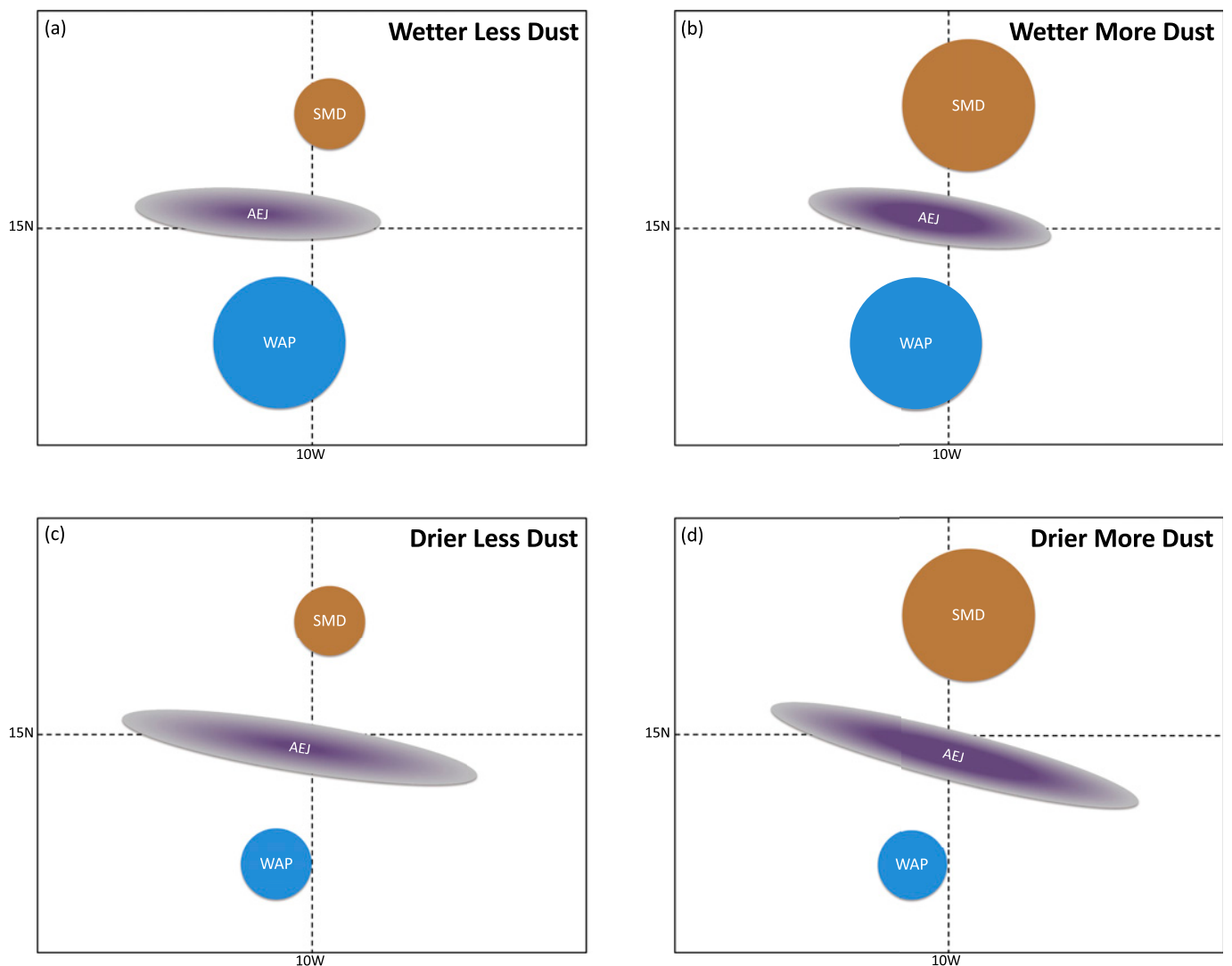

FIG. 10. Schematic of the relationship between the AEJ, SMD, and WAP. Darker shading indicates larger AEJ magnitude and larger circles indicate more SMD and WAP. The location, orientation, and size are not drawn to scale, but rather are intended to show the contrast between WLD, WMD, DLD, and DMD. For clarity, the SMD and WAP fields are shown as separate, but in reality they often overlap.

that the SMD-WAP modified thermal field significantly changes the location, speed, and structure of the AEJ. To test our hypothesis, we use complementary approaches that involve data analysis and numerical modeling. For the data analysis, we use ECMWF, MERRA-2, and TMPA data for July-September spanning 1998-2017 to examine the relationship between the AEJ, SMD, and WAP. For the numerical modeling, we use the Weather Research and Forecasting Model coupled to an interactive dust model to carry out sensitivity tests. Both approaches yield consistent results that confirm our hypothesis.

The SMD-WAP changes to the AEJ are listed in Table 1 and shown schematically in Fig. 10. Our key results are: In dustier years, the AEJ is farther east, stronger, has greater clockwise rotation, has larger zonal asymmetry, and has larger zonal and vertical shears. In wetter years, the AEJ is farther north, higher up, shorter, and has larger meridional shear.

To explain the response of the AEJ to SMD and WAP, we invoke thermal wind balance, a consequence of the pronounced meridional temperature gradient over
North Africa. The central question then is: How do SMD and WAP combine to affect the meridional temperature gradient?

To understand the combined effects of SMD and WAP on the meridional temperature gradient, consider first the region north of the AEJ. In this region, dry convection, orography, and other dynamical mechanisms lift the SMD into the Saharan boundary layer (Cuesta et al. 2009). The SMD then increases atmospheric heating at midlevels (Figs. $3 \mathrm{c}$ and $3 \mathrm{~d}$ and Figs. 9c and 9d), which strengthens the meridional temperature gradient with height (Carlson and Benjamin 1980; Zhu et al. 2007). South of the AEJ, ascent from moist convection also increases atmospheric heating at midlevels through condensational heating (Figs. 3a and $3 \mathrm{~b}$ and Figs. 9a and 9b), but this weakens the meridional temperature gradient with height (Thorncroft and Blackburn 1999). Consequently, the meridional temperature gradient is stronger in drier, dustier years and weaker in wetter, less dusty years.

The response of the AEJ to the SMD-WAP modified thermal field is such that the vertical shear and 
strength of the AEJ are larger in dustier years (Figs. 10b,d), a result of the stronger meridional temperature gradient. The location and structure of the AEJ also vary in response to the SMD-WAP modified thermal field. During wetter years, the AEJ is farther north (Figs. 10a,b), a consequence of the cool, moist air associated with the West African monsoon, which shifts the temperature gradient northward. The weakening of the meridional temperature gradient in wetter years zonally shortens the region occupied by the AEJ core. During dustier years, positive temperature anomalies east of $10^{\circ} \mathrm{W}$ locally increase the meridional temperature gradient and vertical shear, which displaces the AEJ maximum farther east. The competing effects of the SMD and WAP are consistent with the clockwise rotation of the AEJ, where the meridional temperature gradient near the main SMD source regions shifts southward and the meridional temperature gradient in wetter years moves northward.

The relationship between the AEJ, SMD, and WAP has important meteorological consequences. Previous studies have shown that AEWs grow and propagate along the AEJ (Burpee 1972; Reed et al. 1988). Thus the $\sim 1^{\circ}-2^{\circ}$ northward shift of the AEJ found in wetter years equates to a $\sim 100-200-\mathrm{km}$ shift of the entire AEJAEW system. The larger clockwise rotation of the AEJ in dustier years yields an additional $\sim 50 \mathrm{~km}$ northward displacement of the AEJ-AEW system at the west coast of Africa.

Previous modeling studies have shown that SMDmodified AEWs have larger growth rates and energy conversions (Grogan et al. 2016, 2017; Nathan et al. 2017; Bercos-Hickey et al. 2017; Grogan et al. 2019). Here we found that in wetter years the horizontal shear of the AEJ is larger, whereas in dustier years both the horizontal and vertical shears are larger. Because the shearing of the AEJ is intimately connected to the energy conversions with the AEWs (Hsieh and Cook 2007; Bercos-Hickey et al. 2017), we anticipate an increase in barotropic energy conversion during wetter years and an increase in barotropic and baroclinic energy conversion during dustier years.

The results presented in this paper advance understanding of the complex relationship that exists between the AEJ, SMD, and WAP. A logical next step is to study how the SMD and WAP operate separately and in combination to affect the interannual variability of the AEWs and their interaction with the SMD-WAP modified AEJ.

Acknowledgments. The authors thank Dr. Dustin Grogan, Dr. George Kiladis, Dr. Oreste Reale, and two anonymous reviewers for their constructive and insightful comments. We also acknowledge high-performance computing support from Cheyenne provided by NCAR's Computational and Information Systems Laboratory (doi:10.5065/D6RX99HX) and the NASA High-End Computing (HEC) Program through the NASA Advanced Supercomputing (NAS) Division at Ames Research Center (SMD-16-7576). The ECMWF data were retrieved from Cheyenne and the MERRA-2 and TMPA data were retrieved from NASA. This work was supported by NSF Grant 1624414-0.

\section{REFERENCES}

Arkin, P. A., and B. N. Meisner, 1987: The relationship between largescale convective rainfall and cold cloud over the Western Hemisphere during 1982-84. Mon. Wea. Rev., 115, 51-74, https:// doi.org/10.1175/1520-0493(1987)115<0051:TRBLSC >2.0.CO;2.

Bercos-Hickey, E., T. R. Nathan, and S.-H. Chen, 2017: Saharan dust and the African easterly jet-African easterly wave system: Structure, location, and energetics. Quart. J. Roy. Meteor. Soc., 143, 2797-2808, https://doi.org/10.1002/QJ.3128.

Buchard, V., and Coauthors, 2017: The MERRA-2 aerosol reanalysis, 1980 onward. Part II: Evaluation and case studies. J. Climate, 30, 6851-6872, https://doi.org/10.1175/JCLI-D-16-0613.1.

Burpee, R. W., 1972: The origin and structure of easterly waves in the lower troposphere of North Africa. J. Atmos. Sci., 29, 7790, https://doi.org/10.1175/1520-0469(1972)029<0077:TOASOE $>$ 2.0.CO;2.

Carlson, T. N., and S. G. Benjamin, 1980: Radiative heating rates for Saharan dust. J. Atmos. Sci., 37, 193-213, https://doi.org/ 10.1175/1520-0469(1980)037<0193:RHRFSD > 2.0.CO;2.

Chen, S.-H., S.-H. Wang, and M. Waylonis, 2010: Modification of Saharan air layer and environmental shear over the eastern Atlantic Ocean by dust-radiation effects. J. Geophys. Res., 115, D21202, https://doi.org/10.1029/2010JD014158.

, Y.-C. Liu, T. R. Nathan, C. Davis, R. Torn, N. Sowa, C.-T. Cheng, and J.-P. Chen, 2015: Modeling the effects of dustradiative forcing on the movement of Hurricane Helene (2006). Quart. J. Roy. Meteor. Soc., 141, 2563-2570, https:// doi.org/10.1002/QJ.2542.

Chen, T.-C., and H. van Loon, 1987: Interannual variation of the tropical easterly jet. Mon. Wea. Rev., 115, 1739-1759, https:// doi.org/10.1175/1520-0493(1987)115<1739:IVOTTE > 2.0.CO;2.

Cheng, C.-T., W.-C. Wang, and J.-P. Chen, 2010: Simulation of the effects of increasing cloud condensation nuclei on mixedphase clouds and precipitation of a front system. Atmos. Res., 96, 461-476, https://doi.org/10.1016/j.atmosres.2010.02.005.

Chin, M., and Coauthors, 2002: Tropospheric aerosol optical thickness from the GOCART model and comparisons with satellite and sun photometer measurements. J. Atmos. Sci., 59, 461-483, https://doi.org/10.1175/1520-0469(2002)059<0461: TAOTFT $>2.0 . \mathrm{CO} ; 2$.

Cook, K. H., 1999: Generation of the African easterly jet and its role in determining West African precipitation. J. Climate, $\mathbf{1 2}$ 1165-1184, https://doi.org/10.1175/1520-0442(1999)012<1165: GOTAEJ $>2.0 . \mathrm{CO} ; 2$.

Cuesta, J., J. H. Marsham, D. J. Parker, and C. Flamant, 2009: Dynamical mechanisms controlling the vertical redistribution of dust and the thermodynamic structure of the West Saharan 
atmospheric boundary layer during summer. Atmos. Sci. Lett., 10, 34-42, https://doi.org/10.1002/asl.207.

Dee, D. P., and Coauthors, 2011: The ERA-Interim reanalysis: Configuration and performance of the data assimilation system. Quart. J. Roy. Meteor. Soc., 137, 553-597, https://doi.org/10.1002/QJ.828.

DeFlorio, M. J., I. D. Goodwin, D. R. Cayan, A. J. Miller, S. J. Ghan, D. W. Pierce, L. M. Russell, and B. Singh, 2016: Interannual modulation of subtropical Atlantic boreal summer dust variability by ENSO. Climate Dyn., 46, 585-599, https://doi.org/10.1007/s00382-015-2600-7.

Dezfuli, A. K., and S. E. Nicholson, 2011: A note on long-term variations of the African easterly jet. Int. J. Climatol., 31, 20492054, https://doi.org/10.1002/joc.2209.

Diallo, I., M. B. Sylla, M. Camara, and A. T. Gaye, 2013: Interannual variability of rainfall over the Sahel based on multiple regional climate models simulations. Theor. Appl. Climatol., 113, 351-362, https://doi.org/10.1007/s00704-012-0791-y.

Engelstaedter, S., and R. Washington, 2007: Atmospheric controls on the annual cycle of North African dust. J. Geophys. Res., 112, D03103, https://doi.org/10.1029/2006JD007195.

- I. Tegen, and R. Washington, 2006: North African dust emissions and transport. Earth-Sci. Rev., 79, 73-100, https:// doi.org/10.1016/j.earscirev.2006.06.004.

Evan, A. T., C. Flamant, M. Gaetani, and F. Guichard, 2016: The past, present and future of African dust. Nature, 531, 493-495, https://doi.org/10.1038/nature17149.

Fiedler, S., K. Schepanski, B. Heinold, P. Knippertz, and I. Tegen, 2013: Climatology of nocturnal low-level jets over North Africa and implications for modeling mineral dust emission. J. Geophys. Res. Atmos., 118, 6100-6121, https://doi.org/ 10.1002/JGRD.50394.

Gelaro, R., and Coauthors, 2017: The Modern-Era Retrospective Analysis for Research and Applications, version 2 (MERRA-2). J. Climate, 30, 5419-5454, https://doi.org/10.1175/JCLI-D16-0758.1.

Grist, J. P., and S. E. Nicholson, 2001: A study of the dynamic factors influencing the rainfall variability in the West African Sahel. J. Climate, 14, 1337-1359, https://doi.org/10.1175/15200442(2001)014<1337:ASOTDF>2.0.CO;2.

Grogan, D. F. P., T. R. Nathan, and S.-H. Chen, 2016: Effects of Saharan dust on the linear dynamics of African easterly waves. J. Atmos. Sci., 73, 891-911, https://doi.org/10.1175/JAS-D-150143.1.

,$- \ldots$, and -2017 : Saharan dust and the nonlinear evolution of the African easterly jet-African easterly wave system. J. Atmos. Sci., 74, 27-47, https://doi.org/10.1175/JAS-D-16-0118.1.

, - - and 2019: Structural changes in the African easterly jet and its role in mediating the effects of Saharan dust on the linear dynamics of African easterly waves. J. Atmos. Sci., 76, 3351-3365, https://doi.org/10.1175/JAS-D-19-0104.1.

Hall, N. M. J., G. N. Kiladis, and C. D. Thorncroft, 2006: Threedimensional structure and dynamics of African easterly waves. Part II: Dynamical modes. J. Atmos. Sci., 63, 2231-2245, https://doi.org/10.1175/JAS3742.1.

Hastenrath, S., 1990: The relationship of highly reflective clouds to tropical climate anomalies. J. Climate, 3, 353-365, https://doi.org/ 10.1175/1520-0442(1990)003<0353:TROHRC > 2.0.CO;2.

Hess, M., P. Koepke, and I. Schult, 1998: Optical properties of aerosols and clouds: The software package OPAC. Bull. Amer. Meteor. Soc., 79, 831-844, https://doi.org/10.1175/15200477(1998)079<0831:OPOAAC $>2.0 . \mathrm{CO} ; 2$.

Hong, S.-Y., and H.-L. Pan, 1996: Nonlocal boundary layer vertical diffusion in a medium-range forecast model. Mon. Wea. Rev.,
124, 2322-2339, https://doi.org/10.1175/1520-0493(1996)124<2322: NBLVDI $>2.0 . \mathrm{CO} ; 2$

Hsieh, J.-S., and K. H. Cook, 2007: A study of the energetics of African easterly waves using a regional climate model. J. Atmos. Sci., 64, 421-440, https://doi.org/10.1175/JAS3851.1.

Huffman, G. J., and Coauthors, 2007: The TRMM Multisatellite Precipitation Analysis (TMPA): Quasi-global, multiyear, combined-sensor precipitation estimates at fine scales. J. Hydrometeor., 8, 38-55, https://doi.org/10.1175/JHM560.1.

Iacono, M. J., J. S. Delamere, E. J. Mlawer, M. W. Shephard, S. A. Clough, and W. D. Collins, 2008: Radiative forcing by longlived greenhouse gases: Calculations with the AER radiative transfer models. J. Geophys. Res., 113, D13103, https://doi.org/ 10.1029/2008JD009944.

Jones, C., N. Mahowald, and C. Luo, 2003: The role of easterly waves on African desert dust transport. J. Climate, 16, 3617-3628, https://doi.org/10.1175/1520-0442(2003)016<3617: TROEWO $>2.0 . \mathrm{CO} ; 2$.

Kain, J. S., 2004: The Kain-Fritsch convective parameterization: An update. J. Appl. Meteor., 43, 170-181, https://doi.org/ 10.1175/1520-0450(2004)043<0170:TKCPAU>2.0.CO;2.

Kaufman, Y. J., I. Koren, L. A. Remer, D. Tanré, P. Ginoux, and S. Fan, 2005: Dust transport and deposition observed from the Terra-Moderate Resolution Imaging Spectroradiometer (MODIS) spacecraft over the Atlantic Ocean. J. Geophys. Res., 110, D10S12, https://doi.org/10.1029/2003JD004436.

Kleist, D. T., D. F. Parrish, J. C. Derber, R. Treadon, W.-S. Wu, and S. Lord, 2009: Introduction of the GSI into the NCEP global data assimilation system. Wea. Forecasting, 24, 1691-1705, https://doi.org/10.1175/2009WAF2222201.1.

Klüser, L., and T. Holzer-Popp, 2010: Relationships between mineral dust and cloud properties in the West African Sahel. Atmos. Chem. Phys., 10, 6901-6915, https://doi.org/10.5194/acp-10-6901-2010.

Knippertz, P., and M. C. Todd, 2012: Mineral dust aerosols over the Sahara: Meteorological controls on emission and transport and implications for modeling. Rev. Geophys., 50, RG1007, https://doi.org/10.1029/2011RG000362.

Konaré, A., A. Zakey, F. Solmon, F. Giorgi, S. Rauscher, S. Ibrah, and X. Bi, 2008: A regional climate modeling study of the effect of desert dust on the West African monsoon. J. Geophys. Res., 113, D12206, https://doi.org/10.1029/2007JD009322.

Kummerow, C., and L. Giglio, 1994: A passive microwave technique for estimating rainfall and vertical structure information from space. Part I: Algorithm description. J. Appl. Meteor., 33, 3-18, https://doi.org/10.1175/1520-0450(1994) $033<0003$ :APMTFE $>2.0 . C O ; 2$.

Lau, K. M., K.-M. Kim, Y. C. Sud, and G. K. Walker, 2009: A GCM study of responses of the atmospheric water cycle of West Africa and the Atlantic to Saharan dust radiative forcing. Ann. Geophys., 27, 4023-4037, https://doi.org/10.5194/angeo-27-4023-2009.

Lavaysse, C., C. Flamant, S. Janicot, D. J. Parker, J.-P. Lafore, B. Sultan, and J. Pelon, 2009: Seasonal evolution of the West African heat low: A climatological perspective. Climate Dyn., 33, 313-330, https://doi.org/10.1007/s00382-009-0553-4.

- J.-P. Chaboureau, and C. Flamant, 2011: Dust impact on the West African heat low in summertime. Quart. J. Roy. Meteor. Soc., 137, 1227-1240, https://doi.org/10.1002/qj.844.

Marticorena, B., and Coauthors, 2010: Temporal variability of mineral dust concentrations over West Africa: Analyses of a pluriannual monitoring from the AMMA Sahelian dust transect. Atmos. Chem. Phys., 10, 8899-8915, https://doi.org/10.5194/acp-10-8899-2010.

Molod, A., L. Takacs, M. Suarez, and J. Bacmeister, 2015: Development of the GEOS-5 atmospheric general circulation 
model: Evolution from MERRA to MERRA2. Geosci. Model Dev., 8, 1339-1356, https://doi.org/10.5194/gmd-8-1339-2015.

Moron, V., and M. N. Ward, 1998: ENSO teleconnections with climate variability in the European and African sectors. Weather, 53, 287-295, https://doi.org/10.1002/j.1477-8696.1998.tb06403.x.

Nathan, T. R., D. F. P. Grogan, and S.-H. Chen, 2017: Subcritical destabilization of African easterly waves by Saharan mineral dust. J. Atmos. Sci., 74, 1039-1055, https://doi.org/10.1175/ JAS-D-16-0247.1.

,-- , and -2019 : Saharan dust transport during the incipient growth phase of African easterly waves. Geosciences, 9, 388, https://doi.org/10.3390/geosciences9090388.

N'Datchoh, E. T., I. Diallo, A. Konaré, S. Silué, K. O. Ogunjobi, A. Diedhiou, and M. Doumbia, 2018: Dust induced changes on the West African summer monsoon features. Int. J. Climatol., 38, 452-466, https://doi.org/10.1002/joc.5187.

Nicholson, S. E., 2008: The intensity, location and structure of the tropical rainbelt over West Africa as factors in interannual variability. Int. J. Climatol., 28, 1775-1785, https://doi.org/10.1002/joc.1507.

_ 2013: The West African Sahel: A review of recent studies on the rainfall regime and its interannual variability. ISRN Meteor., 2013, 453521, https://doi.org/10.1155/2013/453521.

—_, and J. P. Grist, 2003: The seasonal evolution of the atmospheric circulation over West Africa and equatorial Africa. J. Climate, 16, 1013-1030, https://doi.org/10.1175/15200442(2003)016<1013:TSEOTA $>2.0 . \mathrm{CO} ; 2$.

- B. Some, and B. Kone, 2000: An analysis of recent rainfall conditions in West Africa, including the rainy seasons of the 1997 El Niño and the 1998 La Niña years. J. Climate, 13, 2628-2640, https://doi.org/10.1175/1520-0442(2000)013<2628: AAORRC $>2.0 . \mathrm{CO} ; 2$.

Parker, D. J., and Coauthors, 2005: The diurnal cycle of the West African monsoon circulation. Quart. J. Roy. Meteor. Soc., 131, 2839-2860, https://doi.org/10.1256/QJ.04.52.

Pomposi, C., A. Giannini, Y. Kushnir, and D. E. Lee, 2016: Understanding Pacific Ocean influence on interannual precipitation variability in the Sahel. Geophys. Res. Lett., 43, 9234-9242, https://doi.org/10.1002/2016GL069980.

Randles, C. A., and Coauthors, 2017: The MERRA-2 aerosol reanalysis, 1980 onward. Part I: System description and data assimilation evaluation. J. Climate, 30, 6823-6850, https:// doi.org/10.1175/JCLI-D-16-0609.1.

Reale, O., K. M. Lau, and A. da Silva, 2011: Impact of interactive aerosol on the African easterly jet in the NASA GEOS-5 global forecasting system. Wea. Forecasting, 26, 504-519, https://doi.org/10.1175/WAF-D-10-05025.1.

Reed, R. J., E. Klinker, and A. Hollingsworth, 1988: The structure and characteristics of African easterly wave disturbances as determined from the ECMWF operational analysis/forecast system. Meteor. Atmos. Phys., 38, 22-33, https://doi.org/ 10.1007/BF01029944.

Salah, Z., A. Shalaby, A. L. Steiner, A. S. Zakey, R. Gautam, and M. M. Abdel Wahab, 2018: Study of aerosol direct and indirect effects and auto-conversion processes over the West African monsoon region using a regional climate model. Adv. Atmos. Sci., 35, 182-194, https://doi.org/10.1007/s00376-017-7077-3.

Skamarock, W. C., and Coauthors, 2008: A description of the Advanced Research WRF version 3. NCAR Tech. Note NCAR/TN475+STR, 113 pp., https://doi.org/10.5065/D68S4MVH.

Solmon, F., N. Elguindi, and M. Mallet, 2012: Radiative and climatic effects of dust over West Africa, as simulated by a regional climate model. Climate Res., 52, 97-113, https://doi.org/ 10.3354/cr01039.

Sultan, B., and S. Janicot, 2003: The West African monsoon dynamics. Part II: The "preonset" and "onset" of the summer monsoon. J. Climate, 16, 3407-3427, https://doi.org/10.1175/ 1520-0442(2003)016<3407:TWAMDP >2.0.CO;2.

Sylla, M. B., I. Diallo, and J. S. Pal, 2013: West African monsoon in state-of-the-science regional climate models. Climate Variability, A. Tarhule, Ed., IntechOpen, 3-36.

Tegen, I., and I. Fung, 1994: Modeling of mineral dust in the atmosphere: Sources, transport, and optical thickness. J. Geophys. Res., 99, 22 897-22 914, https://doi.org/10.1029/94JD01928.

Thorncroft, C. D., and M. Blackburn, 1999: Maintenance of the African easterly jet. Quart. J. Roy. Meteor. Soc., 125, 763-786, https://doi.org/10.1002/qj.49712555502.

Waliser, D. E., and R. C. J. Somerville, 1994: Preferred latitudes of the intertropical convergence zone. J. Atmos. Sci., 51, 1619-1639, https://doi.org/10.1175/1520-0469(1994)051<1619: PLOTIC $>2.0 . \mathrm{CO} ; 2$.

Wilcox, E. M., K. M. Lau, and K.-M. Kim, 2010: A northward shift of the North Atlantic Ocean intertropical convergence zone in response to summertime Saharan dust outbreaks. Geophys. Res. Lett., 37, L04804, https://doi.org/10.1029/ 2009GL041774.

Wu, M.-L. C., O. Reale, S. D. Schubert, M. J. Suarez, R. D. Koster, and P. J. Pegion, 2009: African easterly jet: Structure and maintenance. J. Climate, 22, 4459-4480, https://doi.org/ 10.1175/2009JCLI2584.1.

and C. D. Thorncroft, 2012: African easterly jet: Barotropic instability, waves, and cyclogenesis. J. Climate, 25, 1489-1510, https://doi.org/10.1175/2011JCLI4241.1.

Zhu, A., V. Ramanathan, F. Li, and D. Kim, 2007: Dust plumes over the Pacific, Indian, and Atlantic Oceans: Climatology and radiative impact. J. Geophys. Res., 112, D16208, https:// doi.org/10.1029/2007JD008427. 